\title{
Glucose Replacement to Euglycemia Causes Hypoxia, Acidosis, and Decreased Insulin Secretion in Fetal Sheep With Intrauterine Growth Restriction
}

\author{
PAUL J. ROZANCE, SEAN W. LIMESAND, JAMES S. BARRY, LAURA D. BROWN, AND WILLIAM W. HAY, JR. \\ Department of Pediatrics [P.J.R., J.S.B., L.D.B., W.W.H.], University of Colorado Denver and Health Sciences Center, Aurora, Colorado \\ 80045; Department of Animal Sciences [S.W.L.], University of Arizona, Tucson, Arizona 85719
}

\begin{abstract}
Nutritional interventions for intrauterine growth restriction (IUGR) have raised concerns for fetal toxicity, the mechanisms of which are unknown. Most of these attempts did not aim to normalize fetal metabolic conditions. Therefore, we used a model of IUGR to determine whether normalization of fetal hypoglycemia for 2 wks would be tolerated and increase insulin concentrations and pancreatic $\beta$-cell mass. IUGR fetuses received either a direct saline infusion (Sal, the control group) or a $30 \%$ dextrose infusion (Glu) to normalize glucose concentrations. Neither insulin concentrations $(0.11 \pm 0.01 \mathrm{Glu} v$ s. $0.10 \pm 0.01 \mathrm{ng} / \mathrm{mL}$ Sal) nor $\beta$-cell mass $(65.2 \pm$ $10.3 \mathrm{Glu}$ vs. $74.7 \pm 18.4 \mathrm{mg}$ Sal) changed. Glucose stimulated insulin secretion (GSIS) was lower in the Glu group. Glu fetuses became progressively more hypoxic: $\mathrm{O}_{2}$ content $1.4 \pm 0.5$ Glu vs. $2.7 \pm 0.4 \mathrm{mM} \mathrm{Sal}, p<0.05$. Partial pressure of carbon dioxide $\left(\mathrm{PacO}_{2}\right)(53.6 \pm 0.8 \mathrm{Glu}$ vs. $51.6 \pm 0.8 \mathrm{Sal}, p<0.05)$ and lactate (7.74 \pm 3.82 Glu vs. $2.47 \pm 0.55 \mathrm{mM} \mathrm{Sal}, p<0.0001)$ were greater and $\mathrm{pH}$ lower $(7.275 \pm 0.071 \mathrm{Glu} v s .7 .354 \pm 0.003 \mathrm{Sal}, p<0.01)$ in the Glu group. We conclude that correction of fetal hypoglycemia is not well tolerated and fails to increase insulin concentrations or $\beta$-cell mass in IUGR fetuses. (Pediatr Res 65: 72-78, 2009)
\end{abstract}

$\mathbf{I}_{\mathrm{o}}^{\mathrm{n}}$ trauterine growth restriction (IUGR) is an important cause of serious short- and long-term morbidity and increased mortality (1-3). Surprisingly, however, there have been no recent fundamental changes in management-close fetal monitoring and indicated preterm delivery remain the standard options $(1,4)$. Furthermore, there have been few therapeutic trials for IUGR, which have raised concerns for fetal toxicity, the mechanisms of which are unknown (5). Given the serious adverse outcomes of IUGR, it is essential that fetal responses to potential interventions be better understood to develop successful approaches to prevention and treatment. The primary limitation of interventional studies in human cases of IUGR is that immediate physiologic and endocrine consequences for the fetus cannot be assessed directly. Furthermore, previous studies in humans and animal models that aimed to treat IUGR often produced nonphysiologic conditions in the fetus, which often caused even worse fetal pathology.

Received May 28, 2008; accepted August 2, 2008.

Correspondence: Paul J. Rozance, M.D., Department of Pediatrics, Perinatal Research Center, UCDHSC, PO Box 6508, MS F441, Aurora, CO 80045; e-mail: Paul.Rozance@UCHSC.edu

W.W.H. was supported by NIH grants HD42815, DK52138, HD28794, and HD07186, RR00069. P.J.R. was supported by NIH-CNRU Pilot and Feasibility Project 2 P30 DK048520-11 and The Children's Hospital Research Institute Research Scholar Award. S.W.L. was supported by NIH DK067393.
Our hypothesis was that corrections of fetal hypoglycemia to normal physiologic concentrations for $2 \mathrm{wks}$ in late gestation would be well tolerated and improve insulin concentrations and $\beta$-cell mass. We chose to correct fetal hypoglycemia because it is the best characterized nutritional deficiency in IUGR (6-8). To test our hypothesis, we used a sheep model of placental insufficiency and IUGR (PI-IUGR) created by exposing pregnant ewes to elevated ambient temperatures during mid gestation, replicating all the major complications of human IUGR due to placental insufficiency $(9,10)$. Similar to severe human IUGR $(11,12)$ there is hypoglycemia, hypoinsulinemia, and decreased glucose stimulated insulin secretion (GSIS) due to fewer $\beta$-cells $(13,14)$. Insulin deficiency in IUGR is particularly important given the central role this hormone plays in regulating fetal growth (15).

\section{METHODS}

PI-IUGR model. Studies were conducted in pregnant ColumbiaRambouillet ewes in compliance with the Institutional Animal Care and Use Committee, University of Colorado Denver Health Sciences Center at the Perinatal Research Center in Aurora, CO. This laboratory is accredited by the National Institutes of Health, the United States Department of Agriculture, and the American Association for Accreditation of Laboratory Animal Care. PI-IUGR fetuses were created by exposing pregnant ewes to elevated ambient temperatures $\left(40^{\circ} \mathrm{C}\right.$ for $12 \mathrm{~h} ; 35^{\circ} \mathrm{C}$ for $\left.12 \mathrm{~h}\right)$ from $37.6 \pm 0.6 \mathrm{~d}$ gestation age (dGA) until $109.7 \pm 1.1 \mathrm{dGA}$ as previously described (term $148 \mathrm{dGA}$ ) (14). After this exposure, ewes were housed in normothermic environments $\left(20^{\circ} \mathrm{C}\right)$ for the remainder of their studies.

Experimental protocol. Eleven pregnant ewes exposed to elevated ambient temperatures were used for these studies. There was no animal loss during this exposure. Indwelling catheters were surgically placed at $113.8 \pm 1.0 \mathrm{dGA}$ into the ewes and fetuses. Maternal catheters were placed into the femoral artery and vein via a groin incision. Fetal catheters were placed into abdominal aorta and inferior vena cava via pedal incisions (14). In twin gestations, catheters were placed in both fetuses. Two ewes miscarried within 2 days after surgery and before initiation of experimental infusions, leaving nine pregnant ewes with 13 fetuses (5 singletons, 8 twins). These ewes were randomly allocated to a direct fetal dextrose infusion (Glu) or a saline infusion (Sal, the control group). Fetuses from the same mother received the same infusion, resulting in seven Glu fetuses and six Sal fetuses. Infusions were started 4.2 $0.3 \mathrm{~d}$ after surgery (day 0 ). Glu fetuses received $30 \%$ dextrose mixed with $0.9 \% \mathrm{NaCl}$ and adjusted on average twice daily to achieve a fetal arterial plasma glucose concentration of 1.1-1.3 mM, a normal value for this breed of sheep (16). Sal fetuses received a direct fetal infusion of $0.9 \% \mathrm{NaCl}$ at a rate adjusted to match the Glu group. Infusions lasted 13-15 d.

Abbreviations: dGA, days gestational age; Glu, glucose replacement group; GSIS, glucose stimulated insulin secretion; GUR, glucose utilization rate; PI-IUGR, placental insufficiency model of IUGR; Sal, saline infusion group, the control group 
Biochemical analysis. Fetal arterial plasma glucose and lactate concentrations were measured on average twice daily in the Glu fetuses and daily in Sal fetuses. Fetal arterial plasma insulin concentrations, fetal arterial $\mathrm{pH}$, blood gasses, and $\mathrm{Hb}$ concentrations were measured every other day with the exception of the Glu group in which $\mathrm{pH}$, blood gasses, and $\mathrm{Hb}$ concentrations also were also measured on day 14. Fetal arterial plasma amino acids were measured before starting infusions, on day 7, and on the final day of the infusion. Fetal arterial plasma cortisol was measured before starting infusions and on the final day of the infusion. Fetal arterial plasma norepinephrine, insulin like growth factor-1 (IGF-1), and glucagon were measured on the final day of the infusion $(14,17)$.

Norepinephrine concentrations were measured by enzyme-linked immunosorbent assay (ELISA) (Alpco, Windham, NH). Samples were measured in a single assay with repeat determination for a coefficient of variation $(\mathrm{CV})$ greater than 15\%. Insulin (Alpco; interassay and intra-assay CV's: 2.9 and $5.6 \%$ ) and cortisol (Alpco; interassay and intra-assay CV's: 5.7 and 4.4\%) were measured by enzyme-linked immunosorbent assay (14). Glucagon (Linco Research Inc., St Charles, MI; interassay and intra-assay CV's: 11.7 and $6.1 \%$ ) and IGF-1 (Diagnostics Systems Laboratories Inc., Webster, TX; interassay and intra-assay CV's: 4.5 and $2.6 \%$ ) were measured by radio immuno assay (14,17). Amino acids were measured using a Dionex 300 model 4500 analyzer (Dionex, Sunnyvale, CA) (14). Blood gasses, pH, and $\mathrm{Hb}$ concentrations were determined using an ABL 520 analyzer (Radiometer, Copenhagen, Denmark). Oxygen content of the blood was calculated by the ABL 520 analyzer (14).

Insulin and glucagon secretion. On the final day of infusion, a square wave hyperglycemic clamp with a target fetal glucose concentration of 2.4 $\mathrm{mM}$ was used to determine insulin secretion (14). A continuous fetal transfusion of maternal blood $(7 \mathrm{~mL} / \mathrm{h})$ was maintained for the duration of the study to compensate for blood collection. All sample times are relative to the start of the glucose bolus and continuous infusion. Fetal arterial plasma samples were collected at $-25,-15,-5,5,10,15,20,30,45,60,75$, and $90 \mathrm{~min}$. The average of the draws before time 0 represent baseline insulin concentrations and the average of the final three draws represent glucose stimulated insulin concentrations. After these blood draws, a bolus of arginine $(0.5 \mathrm{mmol} / \mathrm{kg}$ estimated fetal weight) in $5 \mathrm{~mL}$ of $0.4 \mathrm{M}$ sodium acetate and $0.9 \% \mathrm{NaCl}$ was injected over 4 min into a fetal venous catheter and fetal arterial plasma samples were collected 5, 10, 20, and 30 min after beginning the bolus.

Organ isolation. Necropsies and organ isolation were performed at the completion of the physiologic studies as previously described (14). The pancreas was weighed, fixed overnight in $4 \%$ paraformaldehyde (wt/vol) in phosphate-buffered saline, and then transferred to $70 \%$ ethanol ( $\mathrm{vol} / \mathrm{vol})$ until it was paraffin embedded.

Fetal pancreatic histology. Tissue sections $(5 \mu \mathrm{m})$ for histologic evaluation were cut from the tail of paraffin-embedded pancreases at $65 \mu \mathrm{m}$ intervals (16). Pancreatic endocrine hormones were identified with guinea pig antiporcine insulin (Dako, Carpinteria CA, 1:500), mouse anti-porcine glucagon (Sigma Chemical Co.-Aldrich, St. Louis, MO, 1:500), rabbit anti-human somatostatin (Dako, 1:500), and rabbit anti-human pancreatic polypeptide (Dako, 1:500). Immunocomplexes were detected with secondary antiserum: anti-rabbit IgG conjugated to Texas Red, anti-mouse IgG conjugated to Cy2, and anti-guinea pig IgG conjugated to 7-amino-4-methylcoumarin-3-acetic acid (Jackson ImmunoResearch Laboratories, West Grove, PA, all 1:500) (16).

Fluorescent images were visualized on a Leica DM5500 microscope equipped with a $10 \times$ objective lens and a Spot Pursuit Camera. Morphometric analysis was performed with ImagePro 6.0 software (Media Cybernetics, Silver Spring, MD). $\beta$-cell (insulin ${ }^{+}$cells) and $\alpha$-cell (glucagon ${ }^{+}$cells) mass were determined by multiplying pancreas weight by the percent of total pancreas area positive for each hormone. For each animal, three tissue sections were used and 10 fields of view were evaluated for each section, which captured almost all of the section for analysis (16).

Statistical analysis. Statistical analysis was performed using SAS version 9.1 or GraphPad Prism 4.0 for Windows $(18,19)$. Results are expressed as mean \pm SEM. A mixed models analysis of variance (ANOVA) was performed to determine effects of treatment group (Glu or Sal), time (days of treatment or minutes of hyperglycemic glucose clamp), and treatment-time interactions for all in vivo measurements except for norepinephrine and IGF-1, which were only measured at the end of the infusion. Covariates were included in the analysis to control for fetal sex, fetal number, and the nonindependent observations made in twin pairs. Weights, fetal length, norepinephrine, IGF-1, and pancreatic endocrine cell areas and mass were compared using the $t$ test or Mann-Whitney test. A paired $t$ test was used to compare maternal core body temperature before and during exposure to elevated ambient temperatures.

\section{RESULTS}

Maternal parameters during treatment. Within 1 week of exposure to elevated ambient temperatures, maternal body temperature increased $\left(39.2 \pm 0.1\right.$ to $39.7 \pm 0.0^{\circ} \mathrm{C}, p<$ 0.0005 ) and reached a plateau thereafter. Daily feed intake was $1.85 \pm 0.09 \mathrm{~kg}$ and daily water intake was $8.1 \pm 0.5 \mathrm{~L}$ with no difference between animals subsequently placed in the Glu or Sal groups. During fetal infusions, there was no difference between groups for maternal arterial plasma glucose $(3.64 \pm 0.14 \mathrm{Glu}, 3.68 \pm 0.15 \mathrm{Sal}, \mathrm{mmol} / \mathrm{L})$ or lactate $(0.611 \pm 0.032 \mathrm{Glu}, 0.624 \pm 0.046 \mathrm{Sal}, \mathrm{mmol} / \mathrm{L})$ concentrations or for maternal feed $(1.35 \pm 0.27 \mathrm{Glu}, 1.17 \pm 0.14 \mathrm{Sal}$, $\mathrm{kg})$ or water $(4.8 \pm 0.6 \mathrm{Glu}, 4.7 \pm 0.6 \mathrm{Sal}$, liters $)$ intakes.

Fetal sex and number. No differences were found in proportions of female fetuses $(67 \% \mathrm{Glu}, 40 \% \mathrm{Sal})$ or singleton fetuses (43\% Glu, 33\% Sal). Sex and fetal number did not have significant effects for any parameters in the mixed models ANOVA.

Glucose and amino acids. The glucose infusion rate required to produce and maintain target fetal arterial plasma glucose concentrations increased progressively (3-fold) over the infusion period (Fig. 1A). Fetal arterial plasma glucose concentrations on day 1 were increased compared with day 0 in the Glu fetuses $(p<0.001)$ and remained increased throughout the infusion (Fig. 1B). In the Sal group, they were decreased on days $6,8,9$, and 14 compared with day $0(p<$ 0.05 ). Fetal arterial amino acid concentrations are shown in Table 1.

Acid-base and blood gas. Glucose treatment had no effect on fetal arterial $\mathrm{Hb}$ concentrations (mean concentrations for the entire infusion period-7.3 $\pm 0.2 \mathrm{Glu}, 6.5 \pm 0.4 \mathrm{Sal}$, $\mathrm{g} / \mathrm{dL})$. Fetal arterial oxygen partial pressure $\left(\mathrm{Po}_{2}\right), \mathrm{O}_{2}$ saturation, and $\mathrm{O}_{2}$ content decreased over time to a greater extent in
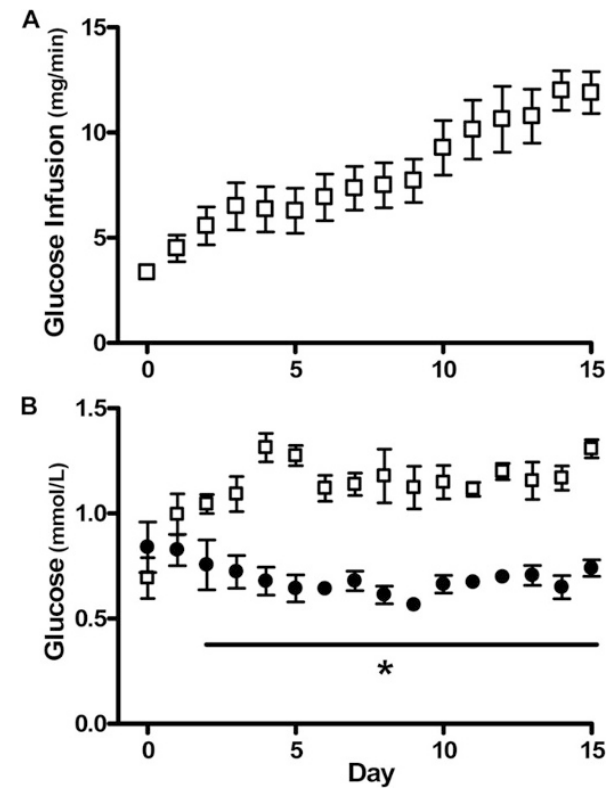

Figure 1. Fetal glucose infusion rates and glucose concentrations. A, Glucose infusion rate in the Glu group. $B$, Fetal arterial plasma glucose concentrations. $\square=$ Glu, $\bigcirc=$ Sal, * = significant difference between Glu and Sal, $p<0.05$ by mixed models ANOVA. Values are mean \pm SEM. 
Table 1. Fetal arterial plasma amino acid concentrations

\begin{tabular}{|c|c|c|c|c|c|}
\hline \multirow[b]{2}{*}{ Amino acid } & \multirow[b]{2}{*}{ Group } & \multicolumn{3}{|c|}{ Duration of infusion } & \multirow[b]{2}{*}{ Reference } \\
\hline & & Day 0 & $1 \mathrm{Wk}$ & $2 \mathrm{Wks}$ & \\
\hline \multicolumn{6}{|c|}{ Treatment differences } \\
\hline \multirow[t]{2}{*}{ Arginine } & Saline & $53 \pm 6$ & $75 \pm 11$ & $87 \pm 11^{*}$ & $78 \pm 6$ \\
\hline & Glucose & $48 \pm 2$ & $52 \pm 7 \dagger$ & $44 \pm 7 \dagger$ & \\
\hline \multirow[t]{2}{*}{ Asparagine } & Saline & $30 \pm 7$ & $43 \pm 8 *$ & $39 \pm 8$ & $38 \pm 1$ \\
\hline & Glucose & $39 \pm 4$ & $32 \pm 5$ & $35 \pm 4$ & \\
\hline \multirow[t]{2}{*}{ Citrulline } & Saline & $154 \pm 7$ & $199 \pm 16^{*}$ & $200 \pm 16^{*}$ & $162 \pm 5$ \\
\hline & Glucose & $130 \pm 8$ & $122 \pm 13 \dagger$ & $114 \pm 13^{*}$ & \\
\hline \multirow[t]{2}{*}{ Cysteine } & Saline & $12 \pm 2$ & $14 \pm 1$ & $13 \pm 1$ & $12 \pm 2$ \\
\hline & Glucose & $15 \pm 3$ & $7 \pm 1 *$ & $8 \pm 1^{* \dagger}$ & \\
\hline \multirow[t]{2}{*}{ Histidine } & Saline & $49 \pm 4$ & $65 \pm 4 *$ & $54 \pm 3$ & $44 \pm 3$ \\
\hline & Glucose & $60 \pm 5$ & $51 \pm 5$ & $58 \pm 5$ & \\
\hline \multirow[t]{2}{*}{ Ornithine } & Saline & $52 \pm 5$ & $69 \pm 9$ & $79 \pm 8^{*}$ & $49 \pm 3$ \\
\hline & Glucose & $45 \pm 4$ & $42 \pm 7 \dagger$ & $36 \pm 2 \dagger$ & \\
\hline \multirow[t]{2}{*}{ Taurine } & Saline & $115 \pm 12$ & $141 \pm 10$ & $121 \pm 12$ & $74 \pm 8$ \\
\hline & Glucose & $182 \pm 17 *$ & $97 \pm 15^{*}$ & $134 \pm 19$ & \\
\hline \multirow[t]{2}{*}{ Threonine } & Saline & $286 \pm 40$ & $297 \pm 31$ & $276 \pm 43$ & $336 \pm 22$ \\
\hline & Glucose & $234 \pm 30$ & $198 \pm 41 \dagger$ & $207 \pm 43^{* \dagger}$ & \\
\hline \multicolumn{6}{|c|}{ No treatment differences } \\
\hline \multirow[t]{2}{*}{ Alanine } & Saline & $291 \pm 32$ & $270 \pm 27$ & $288 \pm 38$ & $295 \pm 16$ \\
\hline & Glucose & $290 \pm 42$ & $280 \pm 40$ & $375 \pm 44$ & \\
\hline \multirow[t]{2}{*}{ Aspartate } & Saline & $17 \pm 3$ & $20 \pm 3$ & $18 \pm 3$ & $18 \pm 1$ \\
\hline & Glucose & $18 \pm 1$ & $16 \pm 2$ & $17 \pm 3$ & \\
\hline \multirow[t]{2}{*}{ Glutamate } & Saline & $34 \pm 3$ & $30 \pm 2$ & $26 \pm 2$ & $41 \pm 4$ \\
\hline & Glucose & $38 \pm 2$ & $35 \pm 6$ & $31 \pm 4$ & \\
\hline \multirow[t]{2}{*}{ Glutamine } & Saline & $374 \pm 41$ & $412 \pm 36$ & $347 \pm 38$ & $370 \pm 12$ \\
\hline & Glucose & $427 \pm 33$ & $353 \pm 40$ & $349 \pm 29$ & \\
\hline \multirow[t]{2}{*}{ Glycine } & Saline & $250 \pm 31$ & $336 \pm 23$ & $339 \pm 25$ & $333 \pm 30$ \\
\hline & Glucose & $324 \pm 32$ & $243 \pm 32$ & $290 \pm 41$ & \\
\hline \multirow[t]{2}{*}{ Isoleucine } & Saline & $97 \pm 3$ & $66 \pm 3^{*}$ & $63 \pm 4^{*}$ & $127 \pm 7$ \\
\hline & Glucose & $106 \pm 6$ & $67 \pm 8^{*}$ & $81 \pm 11^{*}$ & \\
\hline \multirow[t]{2}{*}{ Leucine } & Saline & $154 \pm 2$ & $124 \pm 7$ & $108 \pm 7 *$ & $198 \pm 9$ \\
\hline & Glucose & $196 \pm 13^{*}$ & $109 \pm 13 *$ & $135 \pm 2^{*}$ & \\
\hline Lysine & Saline & $62 \pm 9$ & $95 \pm 11$ & $92 \pm 14$ & $46 \pm 3$ \\
\hline & Glucose & $79 \pm 7$ & $60 \pm 8$ & $75 \pm 18$ & \\
\hline Methionine & Saline & $58 \pm 6$ & $59 \pm 4$ & $55 \pm 5$ & $73 \pm 4$ \\
\hline & Glucose & $77 \pm 13$ & $56 \pm 8$ & $68 \pm 14$ & \\
\hline Phenylalanine & Saline & $101 \pm 9$ & $103 \pm 10$ & $104 \pm 10$ & $130 \pm 6$ \\
\hline & Glucose & $98 \pm 5$ & $70 \pm 6$ & $81 \pm 10$ & \\
\hline Proline & Saline & $165 \pm 32$ & $177 \pm 25$ & $165 \pm 18$ & $113 \pm 7$ \\
\hline & Glucose & $149 \pm 26$ & $132 \pm 30$ & $262 \pm 115$ & \\
\hline Serine & Saline & $680 \pm 109$ & $734 \pm 79$ & $482 \pm 50 *$ & $665 \pm 32$ \\
\hline & Glucose & $679 \pm 80$ & $468 \pm 91 *$ & $392 \pm 94 *$ & \\
\hline Tryptophan & Saline & $40 \pm 1$ & $36 \pm 2$ & $34 \pm 2 *$ & $46 \pm 3$ \\
\hline & Glucose & $34 \pm 2$ & $28 \pm 2 *$ & $31 \pm 2$ & \\
\hline Tyrosine & Saline & $132 \pm 8$ & $101 \pm 5^{*}$ & $102 \pm 11^{*}$ & $165 \pm 10$ \\
\hline & Glucose & $112 \pm 5$ & $88 \pm 9$ & $110 \pm 9$ & \\
\hline Valine & Saline & $422 \pm 24$ & $322 \pm 19 *$ & $285 \pm 22 *$ & $566 \pm 24$ \\
\hline & Glucose & $453 \pm 25$ & $283 \pm 33^{*}$ & $343 \pm 30^{*}$ & \\
\hline
\end{tabular}

Statistics are by mixed models ANOVA. Reference values are obtained from normally grown fetal sheep ( 5 singleton, 8 twins) of the same breed at gestational age $130.2 \pm 0.9$ (Brown and Hay, unpublished).

* Denotes a significant difference within treatment groups compared to baseline.

$\dagger$ Denotes a significant difference between Saline and Glucose within the same time period.

the Glu group vs. the Sal group $(p<0.05$, Fig. $2 A-C)$. Glucose treatment increased fetal arterial $\mathrm{PcO}_{2}\left(\mathrm{Pco}_{2}, p<\right.$ 0.05 , Fig. $2 D$ ). Fetal arterial plasma lactate concentrations increased on days $14-15(p<0.05$, Fig. 2E) and fetal arterial $\mathrm{pH}$ decreased on days $13-15$ in the Glu group $(p<$ 0.05 , Fig. $2 F)$.

Hormone concentrations. Glucose treatment did not affect daily fetal arterial plasma insulin concentrations (Fig. 3). Fetal arterial plasma cortisol concentrations before initiation of the infusion $(6.7 \pm 1.0 \mathrm{Glu}, 9.3 \pm 3.2 \mathrm{Sal}, \mathrm{ng} / \mathrm{mL})$ and at the end of the infusion $(9.9 \pm 3.1 \mathrm{Glu}, 8.9 \pm 1.3 \mathrm{Sal}, \mathrm{ng} / \mathrm{mL})$ were not different between groups. There was an inverse relationship between cortisol concentration and oxygen content at the end of the infusion for all fetuses (Fig. 4A). Fetal arterial plasma IGF-1 concentrations at the end of the infusion were similar in both groups $(11.1 \pm 2.7 \mathrm{Glu}, 10.9 \pm 2.2 \mathrm{Sal}, \mathrm{ng} / \mathrm{mL})$. Fetal arterial plasma norepinephrine concentrations at the end of the infusion showed increased variability in the Glu group $(p<$ 

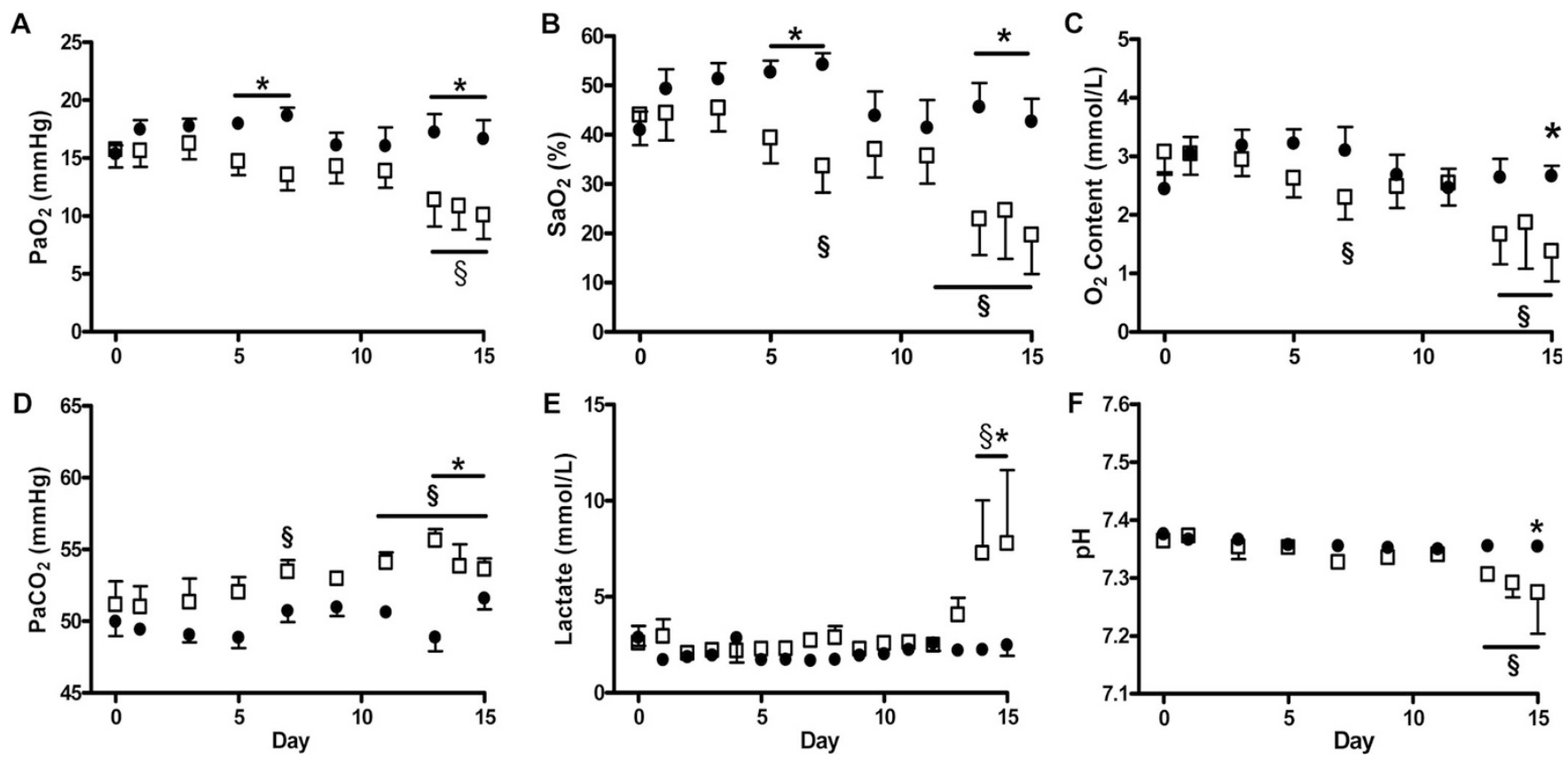

Figure 2. Fetal blood gas and acid-base status. Fetal arterial $\mathrm{Po}_{2}(A), \mathrm{O}_{2}$ saturation $(B), \mathrm{O}_{2}$ content $(C), \mathrm{PCO}_{2}(D)$, lactate $(E)$, and pH $(F)$ are shown with $\mathrm{SEM}$ bars. $\square=\mathrm{Glu}, \bullet=\mathrm{Sal}, *=$ significant difference between Glu and Sal, $\S=$ significant difference compared with day 0 in Glu only, $p<0.05$ by mixed models ANOVA.

$0.005, \mathrm{~F}$ test $)$, but the mean concentrations $(4290 \pm 2100 \mathrm{Glu}$, $1060 \pm 530 \mathrm{Sal}, \mathrm{pg} / \mathrm{mL})$ were not different $(p=0.37$ Mann-Whitney test). There was an inverse relationship between the natural log of norepinephrine concentrations and oxygen content (Fig. 4B). There was a positive relationship

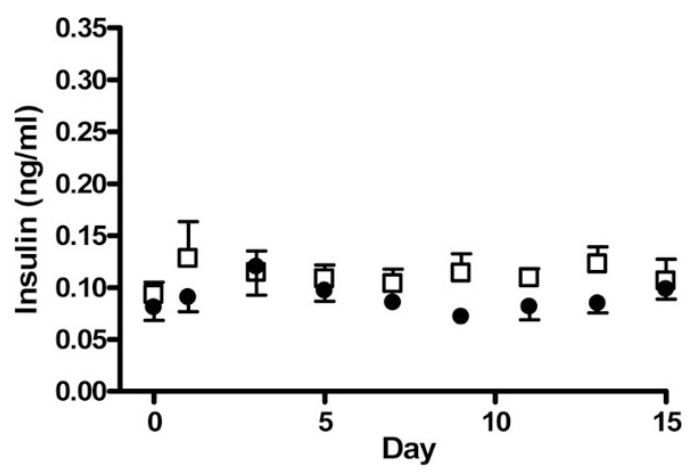

Figure 3. Fetal arterial plasma insulin concentrations. Fetal arterial plasma insulin concentrations with SEM bars. $\square=$ Glu, $\bullet=$ Sal. between fetal plasma arterial cortisol concentrations and the natural log of fetal plasma arterial norepinephrine concentrations (Fig. 4C). Fetal arterial plasma glucagon concentrations at the end of the infusion but before the hyperglycemic clamp showed increased variability in the Glu group $(p<0.01, \mathrm{~F}$ test) but no difference between the means $(78.3 \pm 38.8 \mathrm{Glu}$, $39.6 \pm 9.2 \mathrm{Sal}, \mathrm{pg} / \mathrm{mL})$.

Insulin and glucagon secretion. During the square wave, hyperglycemic clamp glucose concentrations were not different between the groups (Fig. 5A). Chronic glucose treatment negatively effected GSIS. Fetal plasma arterial insulin concentrations increased significantly from baseline by $10 \mathrm{~min}$ in the Sal group, but not until $20 \mathrm{~min}$ in the Glu group. At 10, 45, 75 , and $90 \mathrm{~min}$ of the clamp, insulin concentrations were lower in Glu fetuses compared with Sal fetuses ( $p<0.05$, Fig. 5B). Differences between average maximal insulin concentrations and baseline insulin concentrations were directly associated with fetal arterial $\mathrm{O}_{2}$ content measured before the hyperglycemic clamp (Fig. 5C). Insulin secretion increased after the
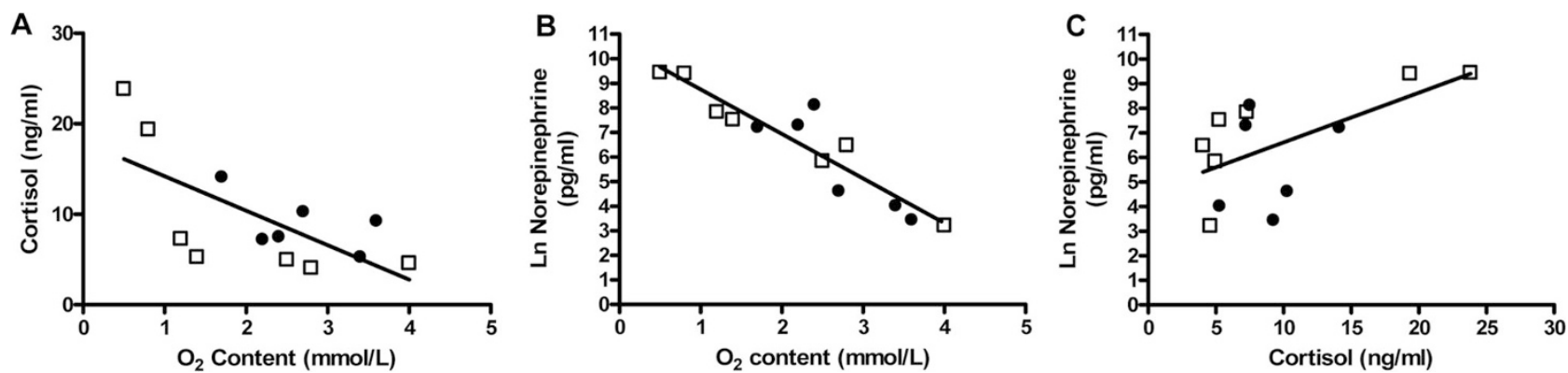

Figure 4. Fetal arterial plasma cortisol and norepinephrine concentrations. A, Fetal arterial plasma cortisol concentrations are plotted as a function of fetal arterial $\mathrm{O}_{2}$ content at the end of the treatment period. $\mathrm{r}^{2}=0.46, p<0.025 . B$. Natural log of fetal arterial plasma norepinephrine concentrations are plotted as a function of fetal arterial $\mathrm{O}_{2}$ content at the end of the treatment period. $\mathrm{r}^{2}=0.86, p<0.0001$. $C$, Fetal arterial plasma cortisol and the natural log of norepinephrine concentrations are plotted for each animal. $\mathrm{r}^{2}=0.34, p<0.05$. For all graphs $\square=$ Glu, $\bullet=$ Sal. 

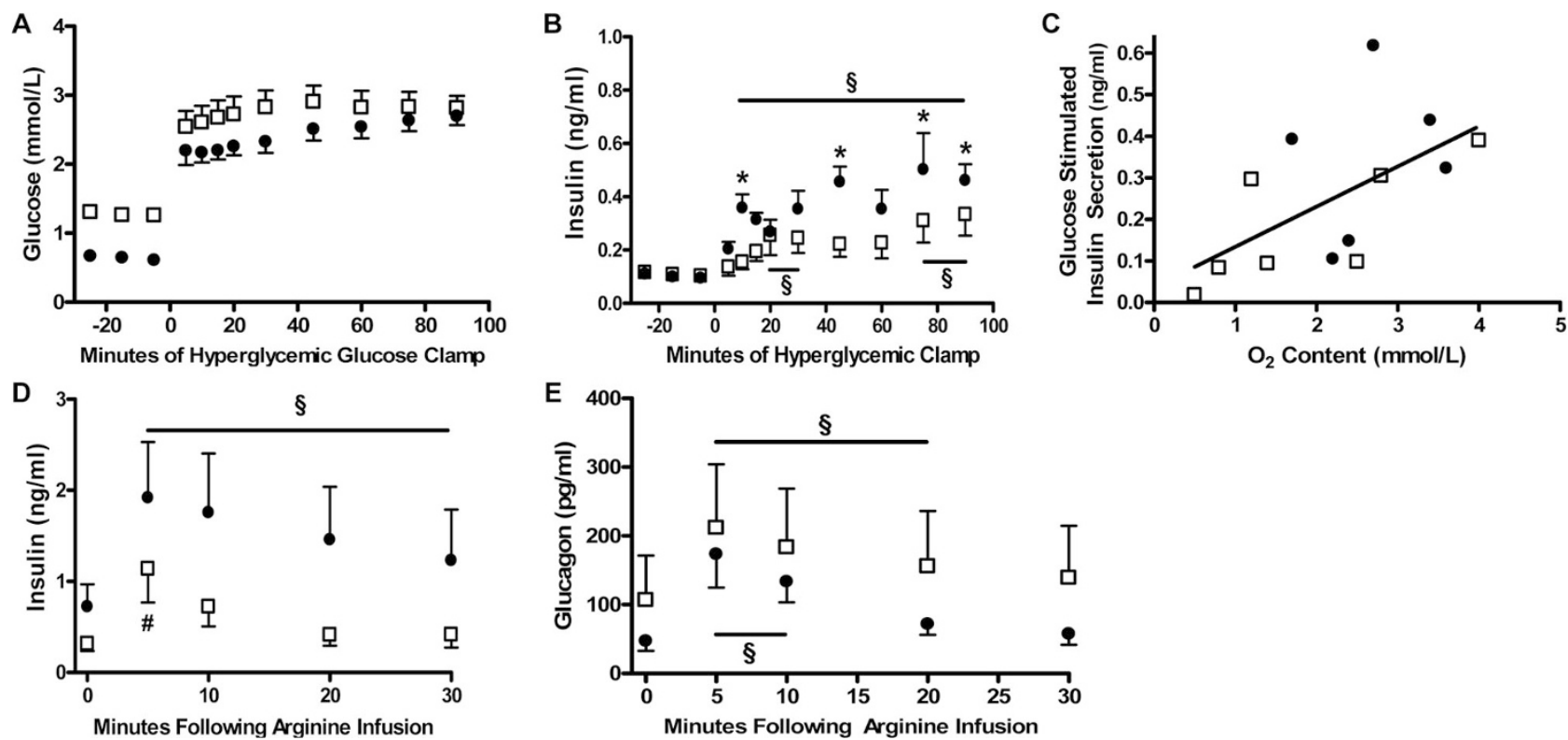

Figure 5. Fetal insulin and glucagon secretion at the end of the treatment period. A, Fetal arterial plasma glucose concentrations \pm SEM during the square wave hyperglycemic clamp started at time $=0 \mathrm{~min} . B$, Glucose stimulated fetal plasma arterial insulin concentrations \pm SEM. $C$, GSIS, defined as the difference between the average glucose stimulated insulin concentrations (time $=60,75$, and $90 \mathrm{~min}$ ) and baseline insulin concentrations (time $=-25,-15$, and -5 min), plotted as a function of fetal arterial $\mathrm{O}_{2}$ content measured before the hyperglycemic clamp, $\mathrm{r}^{2}=0.35, p<0.05$. $D$, Arginine stimulated fetal plasma arterial insulin concentrations \pm SEM measured at the end of the hyperglycemic clamp after bolus administration of arginine at time $=0$ min. $E$, Arginine stimulated fetal plasma arterial glucagon concentrations \pm SEM were measured at the end of the hyperglycemic clamp after bolus administration of arginine at time $=0$ min. For all graphs $\square=\mathrm{Glu}, \boldsymbol{\bullet}=\mathrm{Sal} ; *=$ significant difference between Glu and Sal, $\S=$ significant difference compared with baseline for both groups, $p<$ 0.05 by mixed models ANOVA.

Table 2. Acid-base and blood gas data during the hyperglycemic clamp

\begin{tabular}{|c|c|c|c|c|}
\hline & \multicolumn{2}{|c|}{ Glucose replacement } & \multicolumn{2}{|c|}{ Saline infusion } \\
\hline & Baseline & Hyperglycemic & Baseline & Hyperglycemic \\
\hline $\mathrm{pH}$ & $7.306 \pm 0.041$ & $7.265 \pm 0.044^{*}$ & $7.350 \pm 0.005$ & $7.292 \pm 0.014 *$ \\
\hline $\mathrm{PCO}_{2}(\mathrm{~mm} \mathrm{Hg})$ & $54.8 \pm 1.0$ & $56.3 \pm 1.6$ & $51.7 \pm 0.6$ & $55.6 \pm 0.9^{*}$ \\
\hline Lactate $(\mathrm{mmol} / \mathrm{L})$ & $6.52 \pm 2.79$ & $8.14 \pm 3.02 *$ & $2.60 \pm 0.52$ & $4.75 \pm 0.75^{*}$ \\
\hline $\mathrm{Po}_{2}(\mathrm{~mm} \mathrm{Hg})$ & $11.9 \pm 1.9$ & $11.6 \pm 1.8$ & $16.1 \pm 1.1$ & $14.0 \pm 1.2^{*}$ \\
\hline $\mathrm{O}_{2}$ saturation $(\%)$ & $24.9 \pm 6.4$ & $22.5 \pm 6.1$ & $40.7 \pm 4.1$ & $28.8 \pm 3.9 *$ \\
\hline $\mathrm{O}_{2}$ content $(\mathrm{mmol} / \mathrm{L})$ & $1.89 \pm 0.48$ & $1.71 \pm 0.46$ & $2.67 \pm 0.30$ & $1.9 \pm 0.31 *$ \\
\hline
\end{tabular}

* Indicates a significant change from baseline within treatment group, mixed models ANOVA $(P<0.01)$.

administration of arginine in both groups (Fig. 5D), but the increase was lower in the Glu group.

Maximum arginine stimulated glucagon concentrations were achieved in $5 \mathrm{~min}$ in both groups, tending to be higher in the Glu group (Fig. 5E). During the hyperglycemic clamp, fetal arterial $\mathrm{pH}$ decreased and lactate increased in both groups. Fetal arterial $\mathrm{PCO}_{2}$ increased and $\mathrm{Po}_{2}, \mathrm{O}_{2}$ saturation and $\mathrm{O}_{2}$ content decreased in the Sal group (Table 2).

Fetal measurements, organ weights, and histology of the pancreas. Fetal anthropometric measurements and organ weights are in Table 3. There were no differences between groups in either pancreatic insulin positive area or $\beta$-cell mass. Glucagon positive area and $\alpha$-cell mass were greater in the Glu group than the Sal group $(p<0.05$, Table 4$)$.

\section{DISCUSSION}

We used a placental insufficiency model of IUGR to determine the endocrine and metabolic effects in the IUGR fetus of a chronic glucose infusion designed to produce and maintain
Table 3. Fetal characteristics

\begin{tabular}{lcc}
\hline & $\begin{array}{c}\text { Glucose } \\
\text { replacement }\end{array}$ & $\begin{array}{c}\text { Saline } \\
\text { infusion }\end{array}$ \\
\hline Gestational age (d) & $132.7 \pm 0.8$ & $132.8 \pm 0.7$ \\
Fetal weight (g) & $2355 \pm 272$ & $2174 \pm 160$ \\
Crown rump length (cm) & $41.7 \pm 2.5$ & $43.3 \pm 1.4$ \\
Pancreas (g) & $2.97 \pm 0.28$ & $2.43 \pm 0.21$ \\
Liver (g) & $62.2 \pm 9.2$ & $59.2 \pm 8.7$ \\
Heart (g) & $18.6 \pm 1.6$ & $19.0 \pm 1.2$ \\
Lungs (g) & $70.2 \pm 8.8$ & $67.1 \pm 7.3$ \\
Kidneys (g) & $15.8 \pm 2.8$ & $13.9 \pm 1.4$ \\
Spleen (g) & $5.8 \pm 2.3$ & $5.3 \pm 0.4$ \\
Brain (g) & $38.2 \pm 2.4$ & $42.4 \pm 0.7$ \\
Carcass (g) & $1645 \pm 207$ & $1683 \pm 138$ \\
\hline
\end{tabular}

Values are presented as means $\pm \mathrm{SE}$.

fetal glucose concentrations at euglycemic values. Contrary to our original hypothesis these novel and important results show that correction of fetal hypoglycemia does not increase insulin concentrations or $\beta$-cell mass. This demonstrates that de- 
Table 4. Endocrine pancreas histology

\begin{tabular}{cccc}
\hline & $\begin{array}{c}\text { Glucose } \\
\text { replacement }\end{array}$ & $\begin{array}{c}\text { Saline } \\
\text { infusion }\end{array}$ & $p$ \\
\hline Insulin-positive & $2.1 \pm 0.4$ & $2.9 \pm 0.5$ & 0.23 \\
area (\%) & & & \\
$\beta$-cell mass (mg) & $65.2 \pm 10.3$ & $74.7 \pm 18.4$ & 0.68 \\
Glucagon-positive & $1.1 \pm 0.1$ & $0.6 \pm 0.1$ & $<0.05$ \\
$\quad$ area (\%) & $33.2 \pm 4.4$ & $15.2 \pm 2.2$ & $<0.005$ \\
$\alpha$-cell mass (mg) & 3 & & \\
\hline
\end{tabular}

Values are presented as mean $\pm \mathrm{SE}$.

creased insulin secretion in IUGR is due to either a relatively fixed $\beta$-cell adaptation or some other complication of IUGR besides hypoglycemia. Additionally, glucose replacement causes progressive fetal hypoxia and acidosis indicating a failure of the fetus and/or placenta to adapt to the glucose infusion and allow for normalized growth and metabolism.

Daily insulin concentrations failed to increase, even before the onset of more pronounced fetal hypoxia or acidosis, and $\beta$-cell mass remained unchanged. This may indicate a possible programming effect of placental insufficiency acting to limit insulin secretion even after reestablishment of euglycemia. Alternatively, there may be other complications of IUGR that prevent correction of fetal insulin concentrations and $\beta$-cell mass with euglycemia. These results contrast with a group of normal fetuses made hypoglycemic for 2 wks at the end of gestation. Insulin concentrations and GSIS were decreased, but restoration of euglycemia for $5 \mathrm{~d}$ partially normalized insulin concentrations and secretion (20), demonstrating important differences between the effects of chronic placental insufficiency and relatively shorter term nutrient restriction on $\beta$-cell function $(13,14,16)$.

There was a significant, though not strong, correlation between fetal arterial oxygen content and GSIS. Although hypoxia may explain the decreased GSIS in the glucose treatment group (21), there are other explanations to consider, such as a reduction in the fetal arterial plasma concentrations of several amino acids, including some that stimulate insulin release $(22,23)$. Another possibility is that a direct, constant infusion of glucose into the fetus prevents the normal variation of glucose concentrations that may be important for maintaining GSIS. In a previous experiment in healthy fetal sheep chronic, constant fetal hyperglycemia for 10-11 d decreased GSIS, whereas fluctuating levels of hyperglycemia increased GSIS (24). Therefore, it is possible that lack of short-term variability of fetal glucose concentrations inhibited insulin secretion in this previous study and the current study. Glucose concentrations were not measured with enough frequency to fully address this possibility.

Mean concentrations of other hormones were not significantly different. Glucose treatment did produce greater variability of fetal arterial plasma glucagon and norepinephrine concentrations. Furthermore, glucose treatment increased the pancreatic $\alpha$-cell population. Glucagon is considered a stress response hormone (25) and we can speculate that the glucoseinfused fetuses may have had a stress-related response, which promoted expansion of the $\alpha$-cell population while euglycemia inhibited increased glucagon secretion.
The glucose-infused fetuses developed progressive hypoxia and acidosis; however, the mechanisms could not be fully determined. Uterine and umbilical vein catheters combined with tracer methodologies would be required to measure nutrient and oxygen transfer, utilization, and oxidation rates. Although such studies are planned, we can offer some testable hypotheses to explain the observed changes. One possibility is that glucose infusion in the PI-IUGR fetuses progressively increased the glucose utilization rate (GUR). This would explain the 3-fold increase in the rate of glucose infusion required to maintain euglycemia, which cannot be accounted for by an increase in fetal weight (26). Increased GUR during the infusion also might lead to increased glucose oxidation, $\mathrm{O}_{2}$ utilization, and $\mathrm{CO}_{2}$ production. If $\mathrm{O}_{2}$ transfer to the IUGR fetus with placental insufficiency is limited, then increased glucose metabolism could lead to elevated lactate concentrations. It is also possible that placental glucose oxidation increased progressively (27), which might further limit $\mathrm{O}_{2}$ transfer to the fetus. This would decrease the amount of $\mathrm{O}_{2}$ available to fetal tissues promoting anaerobic metabolism and increased fetal lactate concentrations. Whether increased GUR occurs in the fetus, placenta, or both will require further in vivo experiments and determination of the responsible molecular mechanisms, such as tissue-specific glucose transporter levels and insulin/nutrient signaling.

There are other reports of toxicity after prolonged nutrient infusions in fetal sheep. In one study, inducing marked hyperglycemia for $3 \mathrm{~d}$ with a continuous fetal glucose infusion increased fetal $\mathrm{O}_{2}$ consumption without increasing $\mathrm{O}_{2}$ delivery, decreased fetal arterial oxygen, and transiently increased fetal arterial $\mathrm{PcO}_{2}$. However, there was little change in arterial $\mathrm{pH}$ (28). These results conflict with other studies using maternal glucose infusions to create fetal hyperglycemia for 10-11 d which produced no evidence of fetal hypoxia (24). Because the level of fetal glycemia achieved was similar, the difference between the two studies may be the route of glucose infusion.

Such results led some to conclude that nutrient supplementation without exogenous anabolic hormones in cases of IUGR would be inadvisable, though until now this has not been tested in an animal model that allowed for chronic fetal catheterization and monitoring of fetal blood gasses and acidbase status (29). Our results support the conclusion that a 2-wk euglycemic correction is not well tolerated in IUGR fetuses. Interestingly, and in line with our results, intra-amniotic IGF-1 improved growth in a uteroplacental embolization model of IUGR, but a chronic infusion of both glucose and amino acids reduced the positive effects of IGF-1 on fetal growth and increased fetal lactate concentrations (30).

In conclusion, the present studies provide novel and important evidence that restoring glucose concentrations to euglycemic values in a placental insufficiency model of IUGR causes significant fetal hypoxia and acidosis. We can speculate that metabolic adaptations to chronic placental insufficiency involve mechanisms that enhance rates of glucose metabolism. Interestingly, studies by our group and others have shown maintained or increased fetal glucose utilization and apparent insulin sensitivity at baseline low glucose and 
insulin concentrations of the IUGR fetus (31-33). Short-term infusions of glucose and insulin, however, do not increase fetal GURs more than occurs in normal fetuses at the same glucose and insulin concentrations $(31,33,34)$. Additionally, the present studies define a relatively fixed limitation of pancreatic $\beta$-cell mass and insulin secretion. Such an adaptation may, as already noted, limit the potential imbalance between an increase in an anabolic hormone when nutrient supply is reduced.

The results of this study clearly indicate that constant glucose supplementation alone, particularly just to normal values, will not be effective for correcting and treating IUGR. It remains possible that other nutrients or hormones, alone or in combination, and particularly in the case of glucose if provided, at more natural fluctuating rates, would yield different results. Future studies will be necessary in this model to more thoroughly define the placental and fetal metabolic interactions and the molecular mechanisms that account for the limitation in glucose metabolism. Finally, the inability of glucose correction to improve insulin concentrations or $\beta$-cell mass indicates that either a programmed $\beta$-cell defect or some other complication of IUGR besides hypoglycemia limits improvement after glucose correction. This problem indicates significant potential for later life limitation of pancreatic insulin secretion and the risk of diabetes should insulin resistance also develop.

Acknowledgment. The authors wish to thank John C. Hutton at the Barbara Davis Center for Childhood Diabetes, University of Colorado School of Medicine, for technical expertise with the histology studies.

\section{REFERENCES}

1. Resnik R 2002 Intrauterine growth restriction. Obstet Gynecol 99:490-496

2. Barker DJ, Hales CN, Fall CH, Osmond C, Phipps K, Clark PM 1993 Type 2 (non-insulin-dependent) diabetes mellitus, hypertension and hyperlipidaemia (syndrome X): relation to reduced fetal growth. Diabetologia 36:62-67

3. Hales CN, Barker DJ, Clark PM, Cox LJ, Fall C, Osmond C, Winter PD 1991 Fetal and infant growth and impaired glucose tolerance at age 64. BMJ 303:1019-1022

4. Illanes S, Soothill P 2004 Management of fetal growth restriction. Semin Fetal Neonatal Med 9:395-401

5. Say L, Gülmezoglu AM, Hofmeyr GJ 2003 Maternal nutrient supplementation for suspected impaired fetal growth. Cochrane Database Syst Rev:CD000148

6. Nicolini U, Hubinont C, Santolaya J, Fisk NM, Coe AM, Rodeck CH 1989 Maternal-fetal glucose gradient in normal pregnancies and in pregnancies complicated by alloimmunization and fetal growth retardation. Am J Obstet Gynecol 161:924-927

7. Economides DL, Nicolaides KH 1989 Blood glucose and oxygen tension levels in small-for-gestational-age fetuses. Am J Obstet Gynecol 160:385-389
8. Marconi AM, Paolini C, Buscaglia M, Zerbe G, Battaglia FC, Pardi G 1996 The impact of gestational age and fetal growth on the maternal-fetal glucose concentration difference. Obstet Gynecol 87:937-942

9. Barry JS, Rozance PJ, Anthony RV 2008 An animal model of placental insufficiencyinduced intrauterine growth restriction. Semin Perinatol 32:225-230

10. Barry JS, Anthony RV 2008 The pregnant sheep as a model for human pregnancy. Theriogenology 69:55-67

11. Nicolini U, Hubinont C, Santolaya J, Fisk NM, Rodeck CH 1990 Effects of fetal intravenous glucose challenge in normal and growth retarded fetuses. Horm Metab Res 22:426-430

12. Van Assche FA, De Prins F, Aerts L, Verjans M 1977 The endocrine pancreas in small-for-dates infants. Br J Obstet Gynaecol 84:751-753

13. Limesand SW, Jensen J, Hutton JC, Hay WW Jr 2005 Diminished beta-cell replication contributes to reduced beta-cell mass in fetal sheep with intrauterine growth restriction. Am J Physiol Regul Integr Comp Physiol 288:R1297-R1305

14. Limesand SW, Rozance PJ, Zerbe GO, Hutton JC, Hay WW Jr 2006 Attenuated insulin release and storage in fetal sheep pancreatic islets with intrauterine growth restriction. Endocrinology 147:1488-1497

15. Fowden AL 1992 The role of insulin in fetal growth. Early Hum Dev 29:177-181

16. Rozance PJ, Limesand SW, Zerbe GO, Hay WW Jr 2007 Chronic fetal hypoglycemia inhibits the later steps of stimulus-secretion coupling in pancreatic beta-cells Am J Physiol Endocrinol Metab 292:E1256-E1264

17. de Vrijer B, Davidsen ML, Wilkening RB, Anthony RV, Regnault TR 2006 Altered placental and fetal expression of IGFs and IGF-binding proteins associated with intrauterine growth restriction in fetal sheep during early and mid-pregnancy. Pediatr Res 60:507-512

18. 2003 GraphPad Software. GraphPad Prism version 4.0 for Windows

19. SAS Institute 2004 SAS/STAT ${ }^{\circledR} 9.1$ User's Guide. SAS Publishing

20. Limesand SW, Hay WW Jr 2003 Adaptation of ovine fetal pancreatic insulin secretion to chronic hypoglycaemia and euglycaemic correction. J Physiol 547:95-105

21. Dionne KE, Colton CK, Yarmush ML 1993 Effect of hypoxia on insulin secretion by isolated rat and canine islets of Langerhans. Diabetes 42:12-21

22. Ammon HP, Hehl KH, Enz G, Setiadi-Ranti A, Verspohl EJ 1986 Cysteine analogues potentiate glucose-induced insulin release in vitro. Diabetes 35:13901396

23. Sener A, Best LC, Yates AP, Kadiata MM, Olivares E, Louchami K, Jijakli H, Ladriere L, Malaisse WJ 2000 Stimulus-secretion coupling of arginine-induced insulin release: comparison between the cationic amino acid and its methyl ester. Endocrine 13:329-340

24. Carver TD, Anderson SM, Aldoretta PW, Hay WW Jr 1996 Effect of low-level basal plus marked "pulsatile" hyperglycemia on insulin secretion in fetal sheep. Am J Physiol 271:E865-E871

25. Weise K, Zaritsky A 1987 Endocrine manifestations of critical illness in the child. Pediatr Clin North Am 34:119-130

26. Battaglia FC, Meschia G 1986 An Introduction to Fetal Physiology. Academic Press, Inc., Orlando, Florida, pp 1-27

27. Hay WW Jr, Molina RA, DiGiacomo JE, Meschia G 1990 Model of placental glucose consumption and glucose transfer. Am J Physiol 258:R569-R577

28. Philipps AF, Porte PJ, Stabinsky S, Rosenkrantz TS, Raye JR 1984 Effects of chronic fetal hyperglycemia upon oxygen consumption in the ovine uterus and conceptus. J Clin Invest 74:279-286

29. Harding JE, Bloomfield FH 2004 Prenatal treatment of intrauterine growth restriction: lessons from the sheep model. Pediatr Endocrinol Rev 2:182-192

30. Eremia SC, De Boo HA, Bloomfield FH, Oliver MH, Harding JE 2007 Fetal and amniotic insulin-like growth factor-I supplements improve growth rate in intrauterine growth restriction fetal sheep. Endocrinology 148:2963-2972

31. Limesand SW, Rozance PJ, Smith D, Hay WW Jr 2007 Increased insulin sensitivity and maintenance of glucose utilization rates in fetal sheep with placental insufficiency and intrauterine growth restriction. Am J Physiol Endocrinol Metab 293:E1716-E1725

32. Owens JA, Falconer J, Robinson JS 1989 Glucose metabolism in pregnant sheep when placental growth is restricted. Am J Physiol 257:R350-R357

33. Wallace JM, Milne JS, Aitken RP, Hay WW Jr 2007 Sensitivity to metabolic signals in late gestation growth restricted fetuses from rapidly growing adolescent sheep. Am J Physiol Endocrinol Metab 293:E1233-E1241

34. Owens JA, Gatford KL, De Blasio MJ, Edwards LJ, Mcmillen IC, Fowden AL 2007 Restriction of placental growth in sheep impairs insulin secretion but not sensitivity before birth. J Physiol 584:935-949 